\title{
Synthesis and investigation of polyester and poly amide azo dyes (I)
}

\author{
Rehab Abdeen ${ }^{1,2, ~ *, ~ H . ~ O . ~ B a d r E l d i n ~}{ }^{1}$ \\ ${ }^{1}$ Health science program, Biology Department, Faculty of Science, King Khalid University, Women center Al-Samer, Abha, KSA \\ ${ }^{2}$ Health science program, King Khalid University, P.O. 3340, Saudi Arabia
}

Email address:

Mohamed_abdin60@yahoo.com (R. Abdeen), hanan.oamr@gmail.com (H. O. B. Eldin)

\section{To cite this article:}

Rehab Abdeen, H. O. Badr Eldin. Synthesis and Investigation of Polyester and Poly Amide Azo Dyes (I). American Journal of Applied Chemistry. Vol. 3, No. 1, 2015, pp. 6-13. doi: 10.11648/j.ajac.20150301.12

\begin{abstract}
The preparation of monomer dyes was carried out by formation of diazinium salt of amine compound to coupled with $P$ - toluidine, aniline to form azo dyes with function (hydroxy and amino) groups. the polymerized was carried out with different diacid chloride or modified with acroyl chloride to polymerize with methylmethacrylate (MMA) by two method solution and interfacial poly condensation methods, the prepared mono azodye, poly(ester) and poly(amide) azopolymers were characterized, by infrared spectroscopy, elemental analysis, ${ }^{1} \mathrm{H}$ NMR, thermodynamic (TGA), thermo gravimetric (DSC) analysis and TGA. The molecular weights were measured by GPC. The synthesized polymers showed a good film forming properties.
\end{abstract}

Keywords: Azo Polymers, Polyesters and Polyamides

\section{Introduction}

Azo dye has received great attention due to its environmental stability, ease of preparation and its optical and electrical properties. Much work has been done on the molecular design, synthesis, and assembly of structures with desired properties [ 1-5]. The discovery of diazo compounds occurred around the year 1858, which is parallelto the beginning of what is considered the starting point of modern organic chemistry [6,7]. Studies on polymers with different optical properties have attracted more attention due to their applications in the optical properties [8]. We can classify The Novolac to two types of phenol resins: resold and Novolac. The first one is synthesized under basic $\mathrm{pH}$ conditions with excess formaldehyde, and the second is carried out at acidic $\mathrm{pH}$ (with an excess of phenol). They are widely used in industry because of their chemical resistance, electrical insulation, and dimensional stability [9].

Traditionally, azo dyes are the most important class of commercial dyes, occupying more than half of the dye chemistry. Unlike most organic compounds, dyes possess color because: 1) they absorb light in the visible spectrum $(400-700 \mathrm{~nm}), 2)$ they have at least one chromophore (color-bearing group), 3) they have a conjugated system, i.e. a structure with alternating double and single bonds and 4) they exhibit resonance of electrons, which is a stabilizing force in organiccompounds. When any one of these features is lacking from the molecular structure the color is lost. In addition to chromophores, most dyes also contain groups known as auxochromes (color helpers). Examples of which are carboxylic acid, sulfonic acid, amino, and hydroxyl groups. While these are not responsible for color their presence can shift the color of a colorant and they are most often used to influence dye solubility

In the field of dyestuff chemistry, there is a constant search for new class of dyes which have good fastness properties. The color fastness of the colored fiber is related to the chemical structure, the molecular size of the dye molecule and the physical characteristics of the fiber itself. Giles1 has given some very useful information on the relationship between dye structure, fiber structure, external conditions and behavior of the colored fibers on exposure to light, heat, gaseous impurities and washing (10).

Polymeric dyes were synthesized by four methods: (1) radical polymerization; (2) modification of preformed polymers; (3) condensation polymerization; (4) metal complexing reaction. Polymeric dyes using in textile fields can be classified as crosslinking polymeric dyes, disperse 
polymeric dyes, "fiber-reactive" polymeric dyes and acidic polymeric dyes according to the methods of dyeing fiber (11).

The present paper our approach to design Azo-containing polyamides and polyesters were prepared by polycondensation of azobenzene diacid chloride with specific diamines and diols. In an effort to find the synthetic procedure with high yield, the polycondensation in each case was carried out by two methods, the first is the solution polycondensation in ethanol (chloroform free), with the use of triethylamine (TEA) as an acid acceptor and the second is the interfacial polycondensation in dichloromethane in the presence of sodium carbonate as an acid acceptor, and study the dyeing properties for the prepared azo polymer.

\section{Experimental}

\subsection{Materials}

Sodium hydroxide, Aniline, Sodium nitrite, Aniline hydrochloride was purchased from $p$-Toluidine, Phenol, Resorcinol, Acryloyl chloride, Methylmethacrylate (MMA), Azobiisobutyronitrile (AIBN).

\subsection{Characterization Techniques}

Infrared spectra:IR spectra were recorded on a PERKINERLMER 1430 Ratio Recording Infrared Spectrophotometer from $\mathrm{KBr}$ pellets (microanalysis center, Tanta University, Egypt). Elemental analyses: Elemental analysis were determined on Heraeus (microanalysis center, Cairo University, Giza, Egypt), and PERKIN- ERLMER 2400. Nuclear Magnetic Resonance spectrum ( ${ }^{1} \mathrm{H}$ NMR): ${ }^{1} \mathrm{H}-\mathrm{NMR}$ were recorded on Varian $300 \mathrm{M}$, Mercury-oxford and on a Jeol JNM-PM X90 SI NMR spectroscopy. Thermal analysis (TA): A Mettler TA 4000 System instrument consisting of DSC-30 differential scanning calorimeter, TGA-50 furnace with a M3 microbalance, and TA72 Graphware software were employed for thermal analysis. DSC samples of ca. $5 \mathrm{mg}$ were weighed in $40 \mu \mathrm{l}$ aluminium pan and an empty pan was used as reference. Measurements were carried out under $80 \mathrm{ml} \cdot \mathrm{min}^{-1}$ nitrogen flow rate according to the following protocol: first and second heating from $0{ }^{\circ} \mathrm{C}$ to $140{ }^{\circ} \mathrm{C}$ at $10^{\circ} \mathrm{C} \cdot \mathrm{min}^{-1}$; first cooling (quenching) from $140{ }^{\circ} \mathrm{C}$ to $0^{\circ} \mathrm{C}$ at $100{ }^{\circ} \mathrm{C} \cdot \mathrm{min}^{-1}$; and second heating from $0{ }^{\circ} \mathrm{C}$ to $300{ }^{\circ} \mathrm{C}$ at $10{ }^{\circ} \mathrm{C} \cdot \mathrm{min}^{-1}$. TGA evaluations were performed on 5-6 $\mathrm{mg}$ samples at $10^{\circ} \mathrm{C} \cdot \mathrm{min}^{-1}$ from $25^{\circ} \mathrm{C}$ to $700{ }^{\circ} \mathrm{C}$, under $200 \mathrm{ml} \cdot \mathrm{min}^{-1}$ nitrogen flow rate.

\section{Synthesis of Monomers}

\subsection{Synthesis of 4-(2', 4'-Dihydroxyphenylazo) Phenol (I)}

p-Aminophenol, $5.45 \mathrm{~g}$ (50 mmol) was dissolved in a mixture of $6 \mathrm{~g}$ of concentrated sulphuric acid $(3.3 \mathrm{ml}, 33$ mmol), $25 \mathrm{ml}$ water and $25 \mathrm{~g}$ of ice. The solution was cooled with stirring in ice bath until become clear, then a solution of $3.45 \mathrm{~g}$ (50 mmol) of sodium nitrite in $7.5 \mathrm{ml}$ water was added dropwise during $10 \mathrm{~min}$, and the reaction mixture was further stirred for $20 \mathrm{~min}$ in an ice bath at $0-5{ }^{\circ} \mathrm{C}$. The solution was added dropwise to $5.5 \mathrm{~g}(50 \mathrm{mmol})$ of resorcinol in $10 \%$ sodium hydroxide solution with stirring in an ice bath for further $1 \mathrm{~h}$, where by a red product was precipitated. The productwas collected by filtration and washed with water $(3 \mathrm{x})$ and dried under vacuum at room temperature overnight. The product with molecular formula $\mathrm{C}_{12} \mathrm{H}_{10} \mathrm{~N}_{2} \mathrm{O}_{3}$ and molecular weight (230.223) was obtained in $91 \%$ yield.

\subsection{Synthesis of 4, 4-Bis (1"-Azo-4"-Aminobenzene) Biphenyl (II)}

Benzedine, $1.9 \mathrm{~g}$ (10 mmol) was dissolved in $8 \mathrm{ml}$ of conc. hydrochloric acid and $90 \mathrm{ml}$ water. The solution was cooled to $2{ }^{\circ} \mathrm{C}$, and then $5 \mathrm{ml}$ of the sodium nitrite solution $(1.5 \mathrm{~g}$ of sodium nitrite in $5 \mathrm{ml}$ of water) was added dropwise, below $5^{\circ} \mathrm{C}$. The reaction mixture was stirred for another $1 \mathrm{~h}$ at $5^{\circ} \mathrm{C}$, and then was filtered. The filtrate was added dropwise to the aniline solution, $(1.92 \mathrm{~g}, 20 \mathrm{mmol})$ aniline in $5 \mathrm{ml}$ hydrochloric acid and $50 \mathrm{~mL}$ water. The solution was stirred for $1 \mathrm{~h}$, and neutralized with a solution of sodium acetate, then kept overnight. The formed yellow azo product was filtered off, washed with water $(3 \mathrm{x})$, and then dried under vacuum at room temperature overnight. The product with molecular formula $\mathrm{C}_{24} \mathrm{H}_{20} \mathrm{~N}_{6}$ and molecular weight (392.46) was obtained in $90 \%$ yield.

\subsection{Synthesis of 4, 4'-Bis (1"-Azo-2", 4"-Dihydroxybenzene) Biphenyl (III)}

A solution of nitrosyl sulphuric acid was prepared by careful addition of $1.44 \mathrm{~g}$ of sodium nitrite to $10 \mathrm{ml}$ of concentrated sulphuric acid. The solution was cooled to $3^{\circ} \mathrm{C}$ and $10 \mathrm{ml}$ of mixed acids (1 part propionic acid and 5 parts acetic acid) was added at $10^{\circ} \mathrm{C}$. Benzedine (1.13 g, $\left.10 \mathrm{mmol}\right)$ was then added, followed by addition a further $10 \mathrm{ml}$ of the mixed acids. The reaction mixture was stirred for $2 \mathrm{~h}$ at $-5{ }^{\circ} \mathrm{C}$, before being added to a cooled solution of $(20 \mathrm{mmol})$ resorcinol in $10 \mathrm{ml}$ of $10 \%$ sodium hydroxide solution. The resulting precipitate was filtered off, washed with water and purified by recrystallization from ethanol/water, and then dried under vacuum at room temperature overnight. A product with molecular formula $\mathrm{C}_{24} \mathrm{H}_{18} \mathrm{~N}_{4} \mathrm{O}_{4}$ and molecular weight (426.43) was obtained in $82 \%$ yield.

\subsection{Synthesis of p-Aminoazobenzene (III)}

Aniline $14 \mathrm{~g}(13.7 \mathrm{ml}, 150 \mathrm{mmol})$ was dissolved in a mixture of $75 \mathrm{ml}$ water, $20 \mathrm{ml},(640 \mathrm{mmol})$ of concentrated hydrochloric acid, and $50 \mathrm{~g}$ of ice. A solution of $5.2 \mathrm{~g}$ (75 mmol) sodium nitrite in $20 \mathrm{ml}$ water was added dropwise with continuous stirring for $15 \mathrm{~min}$. Then a solution of $21 \mathrm{~g}$ sodium acetate in $40 \mathrm{ml}$ water was added during $5 \mathrm{~min}$. A yellow precipitate of diazoaminobenzene was separated, allowed to stand for $45 \mathrm{~min}$ in an ice bath at $20^{\circ} \mathrm{C}$, and then it was filtered off and washed with water.

A mixture of $5 \mathrm{~g}$ (25 mmol) of diazoaminobenzene, in $15 \mathrm{ml}$ aniline and $2.5 \mathrm{~g}(19 \mathrm{mmol})$ of aniline hydrochloride was shaken in water bath at $50{ }^{\circ} \mathrm{C}$ for $1 \mathrm{~h}$, then was allowed to stand for $30 \mathrm{~min}$ and $15 \mathrm{ml}$ of glacial acetic acid and $15 \mathrm{ml}$ 
water was added. The separated product $p$-aminoazobenzene(IV)was collected by filteration and washed with water $(3 \mathrm{x})$ and dried under vacuum at room temperature overnight. The product with molecular formula $\mathrm{C}_{12} \mathrm{H}_{11} \mathrm{~N}_{3}$ and molecular weight (197.24) was obtained in $75 \%$ yield.

\subsection{Synthesis of 4-Methyl-2', -Dihydroxyazobenzene (V)}

p-Toluidine (10.7 g, $100 \mathrm{mmol})$ was dissolved in a mixture of $24 \mathrm{ml}(660 \mathrm{mmol})$ of concentrated hydrochloric acid, $24 \mathrm{ml}$ of water and $24 \mathrm{~g}$ of ice. The reaction mixture was cooled in an ice-salt bath and a solution of $6.9 \mathrm{~g}(100 \mathrm{mmol})$ of sodium nitrite in $25 \mathrm{ml}$ of water was added dropwise. The reaction mixture was stirred while cooling for 20 min and the solution was added dropwise to a cooled solution of $11 \mathrm{~g}(100 \mathrm{mmol})$ of resorcinol in $5 \mathrm{ml}$ of $10 \%$ sodium hydroxide solution. The product 3-methyl-2 , 4-dihydroxyazobenzene (V)was collected by filtration and washed with water $(3 \mathrm{x})$ and dried under vacuum at room temperature overnight. The product with molecular formula $\mathrm{C}_{13} \mathrm{H}_{12} \mathrm{~N}_{3} \mathrm{O}_{2}$ and molecular weight (228.25) was obtained in $73 \%$ yield.

\subsection{Synthesis of 4-Methyl-4-Hydroxyazobenzene (VI)}

$p$-Toluidine $10.7 \mathrm{~g}(100 \mathrm{mmol})$ was dissolved in a mixture of $24 \mathrm{ml}$ ( $660 \mathrm{mmol})$ of concentrated hydrochloric acid, $24 \mathrm{ml}$ of water and $24 \mathrm{~g}$ of ice. The reaction mixture was cooled in ice-salt, and a solution of $6.9 \mathrm{~g}(100 \mathrm{mmol})$ of sodium nitrite in $25 \mathrm{ml}$ of water was added dropwise, and stirring was continued for further $20 \mathrm{~min}$. The solution was added dropwise to a cooled solution of $9.4 \mathrm{~g}(100 \mathrm{mmol})$ of phenol in $5 \mathrm{ml}$ of $10 \%$ sodium hydroxide solution. The product 4-methyl-4-hydroxyazobenzene (VI) was collected by filtration and washed with water $(3 \mathrm{x})$ and dried under vacuum at room temperature overnight. The product with molecular formula $\mathrm{C}_{13} \mathrm{H}_{12} \mathrm{~N}_{2}$ Oand molecular weight (212.25) was obtained in $70 \%$ yield.

\subsection{Reaction of 4-Methyl 4-Hydroxyazobenzene (VI) with Acryloyl Chloride}

4-Methylazobenzene-4-acrylate (VII) was prepared using the following quantities: $2.12 \mathrm{~g}(10 \mathrm{mmol})$ of 4-methyl 4-hydroxyazobenzene (VI) and $0.905 \mathrm{~g}$ (10 mmol, $0.812 \mathrm{ml})$ of acryloyl chloride in dry pyridine. The product 4-methylazobenzene-4-acrylate (VII) with molecular formula $\mathrm{C}_{16} \mathrm{H}_{14} \mathrm{~N}_{2} \mathrm{O}_{2}$ and molecular weight (266.3) was obtained in $66 \%$ yield.

\subsection{Polymerization of dyes with Azelic Diacid Chlorides}

Polycondensation of dyes with azelic diacid chlorides were carried out by two methods as follows:

\subsubsection{Solution Polycondensation Method}

Polycondensation of 4-(2', 4'-dihydroxyphenylazo) phenol (I) with azelic diacid chlorides were achieved by the reaction of the components in dry ethanol free chloroform.

To a cooled solution of $(10 \mathrm{mmol})$ of the azelyl diacid chloride in $15 \mathrm{ml}$ of dry ethanol free chloroform, $18 \mathrm{~mL}$ of TEA was added in a $100 \mathrm{~mL}$ round bottomed flask. The reaction mixture was stirred in an ice bath at $-10{ }^{\circ} \mathrm{C}$ for $15 \mathrm{~min}$, then a solution of (10 mmol) of dye (I), in $25 \mathrm{ml}$ dry ethanol free chloroform, was added dropwise with constant stirring. The reaction mixture was further stirred at $-10{ }^{\circ} \mathrm{C}$ for $30 \mathrm{~min}$ then for $48 \mathrm{~h}$ at room temperature .The chloroform layer was extracted with $0.1 \mathrm{M} \mathrm{HCl}(3 \mathrm{X}), 0.1 \mathrm{M} \mathrm{NaOH}(3 \mathrm{X})$ and finally with water. The chloroform layer was dried over anhydrous $\mathrm{MgSO}_{4}$ overnight at room temperature. The $\mathrm{MgSO}_{4}$ was then filtered and the chloroform was evaporated on rotary evaporator and the products were further dried under vacuum at room temperature overnight.

\subsubsection{Interfacial Polymerization Method}

Interfacial polycondensation of dyes with azelic diacid chlorides were achieved by the reaction of the components in methylene chloride.

A solution of $(10 \mathrm{mmol})$ of dye in $45 \mathrm{~mL}$ water, 2 drops of pyridine and $13 \mathrm{~mL}$ dichloromethane was vigorously stirred. Then a solution of (10 mmol) of azelyl diacid chloride in 27 $\mathrm{mL}$ of dichloromethane was added with constant stirring for 10 min. Products was collected by filtration using G4 sintered glass funnel, washed $(3 \mathrm{x})$ with dichloromethane, and dried under vacuum at room temperature overnight.

\subsection{Copolymerization with Methyl Methacraylate (MMA)}

The title compound was prepared from compound (XI) using the following quantities: $0.285 \mathrm{~g}(1 \mathrm{mmol})$ of compound (XI), $10 \mathrm{~g}$ (100 mmol) of MMA and $0.1 \mathrm{~g}$ of AIBN in 1 , 4-dioxane. The yield of the product (LVI) was (70\%). The product (LVI). A series of copolymers were synthesized by using different ratios of compound (XI) as listed in Table (1).

Table 1. Ratio of modified azo dye to MMA.

\begin{tabular}{llll}
\hline $\begin{array}{l}\text { Code of } \\
\text { copolymer }\end{array}$ & \% of azo compound & \% of (MMA) & Yield \% \\
\hline LVII & 10 & 90 & 75 \\
LX & 40 & 60 & 75 \\
\hline
\end{tabular}

\section{Results and Discussion}

\subsection{Synthesis of 4-(2', 4'-Dihydroxyphenylazo) Phenol}

4-(2', 4'-dihydroxyphenylazo) phenol (I) was prepared by subsequent diazotization and coupling of the diazonium salt of $p$-aminophenol with resorcinol. Diazotization was carried out by the usual procedure using sodium nitrite and sulphuric acid and coupling was done in moderately alkaline medium at $0-5^{\circ} \mathrm{C}$ as shown in Scheme (1). An orange red dye with $92 \%$ yield was produced, the structure of (I) was confirmed by elemental analysis and the data are listed in Table (2), they are in a good agreement with the calculated values.

The IR spectrum of the azodye as in Table (3) showed the appearance of peak at $1455 \mathrm{~cm}^{-1}, 1594 \mathrm{~cm}^{-1}$ for $(-\mathrm{N}=\mathrm{N}-)$ group and at $3424 \mathrm{~cm}^{-1}$ for $(-\mathrm{OH})$ group, confirmed the formation of the azodye. ${ }^{1} \mathrm{H}$ NMR (in $\left.\mathrm{d}_{6}-\mathrm{DMSO}\right): \delta=7.0-7.7 \mathrm{ppm}(m, 7 \mathrm{H}, \mathrm{Ar} \underline{\mathrm{H}}$ ), and $\delta=6.30,12.4 \mathrm{ppm}(s, 3 \mathrm{H}, 3 \mathrm{OH})$ as shown in Table (4). 


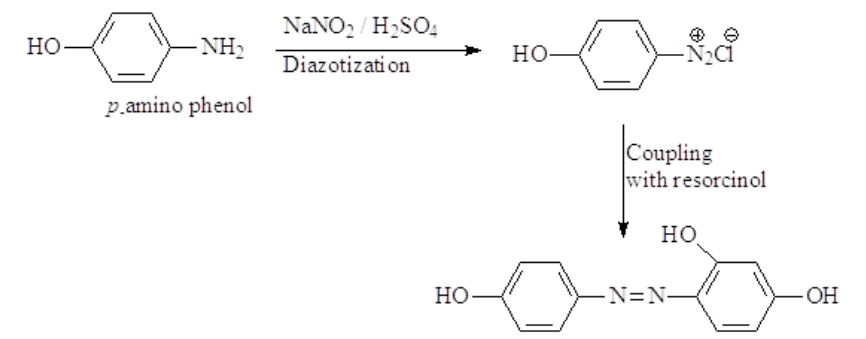

Scheme 1. Synthetic route of 4-(2', 4'-dihydroxyphenylazo) phenol.

\subsection{Polymerization of 4-(2', 4'-Dihydroxyphenylazo) Phenol with Azeil Dichloride}

The polycondensation was carried out by two methods, the first is solution polycondensation in ethanol free chloroform with the use of triethylamine (TEA) as an acid acceptor and the second is interfacial polycondensation in dichloromethane with the use of sodium carbonate as an acid acceptor.

\subsubsection{Solution Polycondensation}

The solution polycondensation of the diacid chlorides was carried. The amount of the diacid chloride was added to $\mathrm{OH}$ terminated azo monomer, 4-(2', 4'-dihydroxyphenylazo) phenol in the presence of dry TEA as an acid acceptor to form the corresponding azopolyester. The reactions were conducted at low temperature then at room temperature under anhydrous condition as outlined in Scheme (2). Both polymer products were obtained in high yields.

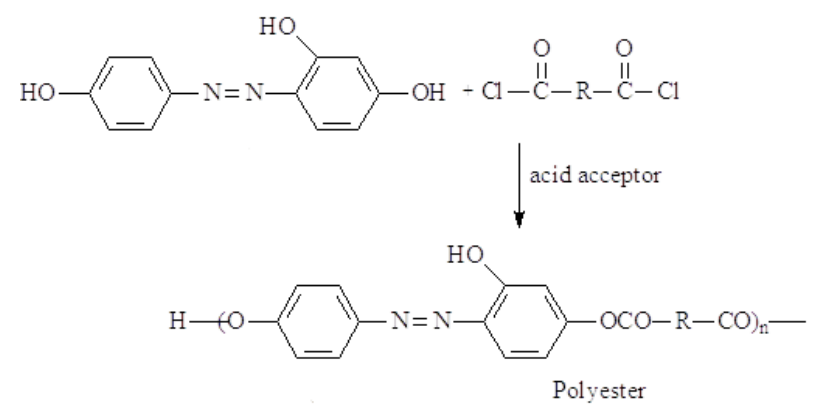

Scheme 2. Synthetic route of copolymer of 4-(2', 4'-dihydroxyphenylazo) phenol with various acid chlorides.

The elemental analyses of the synthesized azopolyesters were in a good agreement with the calculated values as shown in Table (2). The IR spectra of the azopolymers as in Table (3) showed peaks at $1600-1729 \mathrm{~cm}^{-1}$ for $(\mathrm{C}=\mathrm{O})$ in $(\mathrm{COOR})$, at $1110-1256 \mathrm{~cm}^{-1}$ for $(\mathrm{C}-\mathrm{O})$ in (COOR), the disappearance of the peak at $701 \mathrm{~cm}^{-1}$ for $(-\mathrm{C}-\mathrm{Cl})$ and the appearance of peak at 2925-2977 $\mathrm{cm}^{-1}$ for $(\mathrm{CH})_{\text {alph }}$ confirmed the formation of polyester.

\subsubsection{Interfacial Polycondensation}

A solution of the diacid chloride in dry methylene chloride was added to 4-(2', 4'-dihydroxyphenylazo) phenol (I) in (water-methylene chloride) mixture in the presence of pyridine as acid acceptor as shown in Scheme (2). This method is faster than solution polycondensation, but with low yield as a result of hydrolysis apart of azobenzene diacid chloride. The elemental analysis and the IR spectra of the synthesized azopolyesters were similar to the azopolyesters synthesized via solution polycondensation method.

Table 2. Elemental analysis ofazo dyes and its copolymer.

\begin{tabular}{lllllll}
\hline \multirow{2}{*}{ Polymer } & C\% & \multicolumn{3}{c}{ H\% } & N\% \\
\cline { 2 - 7 } & Calc. & Found & Calc. & Found & Calc. & Found \\
\hline I & 62.60 & 59.45 & 4.37 & 4.62 & 12.12 & 11.77 \\
XXXV & 65.70 & 62.90 & 6.00 & 5.41 & 7.93 & 7.30 \\
II & 73.46 & 72.92 & 5.13 & 4.57 & 21.40 & 21.30 \\
XLII & 72.66 & 67.92 & 6.05 & 6.35 & 15.40 & 13.70 \\
VIII & 68.41 & 64.29 & 5.3 & 5.48 & 12.28 & 11.3 \\
LVII & 62.02 & 62.08 & 7.17 & 7.41 & 2.37 & 1.33 \\
LX & 62.99 & 64.49 & 6.04 & 5.58 & 7.1 & 6.62 \\
IX & 73.57 & 72.53 & 5.7 & 5.75 & 13.2 & 12.59 \\
XII & 72.17 & 71.4 & 5.3 & 5.44 & 10.5 & 10.34 \\
\hline
\end{tabular}

\subsection{Synthesis of 4, 4'-bis (1"-azo-4"-Aminobenzene)} Biphenyl (II)

A procedure using sodium nitrite and sulphuric acid, and coupling of the diazonium salt with aniline was done in moderately acidic medium at $0-5^{\circ} \mathrm{C}$, to give a yellow dye of 4 , 4'-bis (1"-azo-4"-aminobenzene) biphenyl (II) as shown in Scheme (3). The azo dye (II) was in yield $(90 \%)$, and its structure was conformed by elemental analysis. The data as given in Table (2), it was in good agreement with the calculated values. IR spectrum of the dye (II) showed the appearance of peak at $1517 \mathrm{~cm}^{-1}, 1453 \mathrm{~cm}^{-1}$ for $(-\mathrm{N}=\mathrm{N}-)$, at $1614 \mathrm{~cm}^{-1}$ for $\left(-\mathrm{NH}_{2}\right)$ which confirmed the formation of the azo dye as in Table (3).

${ }^{1} \mathrm{H}$ NMRspectrum for dye (II) was recorded in $\left(\mathrm{d}_{6}\right.$-DMSO) and showed the following peaks: $\delta=7.0-8.0 \mathrm{ppm}(m, 12 \mathrm{H}$, $\operatorname{Ar} \underline{\mathrm{H}})$, and $\delta=12.4 \mathrm{ppm}\left(\mathrm{s}, \mathrm{H}, 2 \mathrm{NH}_{2}\right)$. Table (4).

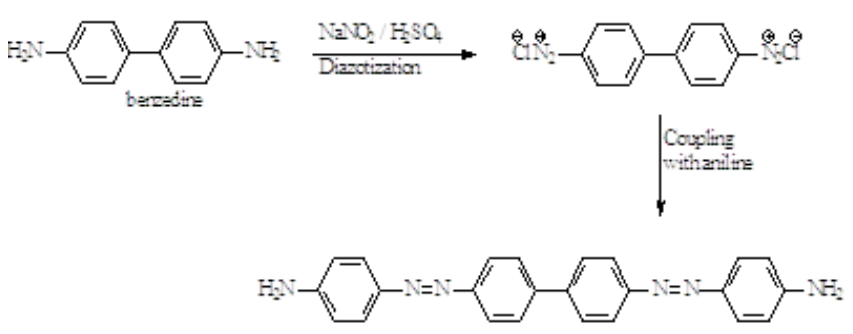

Scheme 3. Synthetic route of 4, 4-bis (1"-azo-4"-aminobenzene) biphenyl.

\subsection{Polymerization of 4, 4|-Bis (1"-azo-4"-Aminobenzene) Biphenyl with Azeil Dichloride}

The polymerization 4, 4-bis (1"-azo-4"-aminobenzene) biphenyl was carried out by two methods, the first is solution polycondensation in ethanol free chloroform, with the use of triethylamine (TEA) as an acid acceptor, and the second is the interfacial polycondensation in dichloromethane with the use of pyridine as an acid acceptor.

\subsubsection{Solution Polycondensation}

Biodegradable azo-containing polyamides were prepared by solution polycondensation of azo monomer, 4, 4-bis 
(1"-azo-4"-aminobenzene) biphenyl (II) with Azeil dichloride. It was carried out similarly to solution poly condensation procedure for azo polyester prepared from 4-(2', 4'-dihydroxyphenylazo) phenol (I) with Dithiodipropyl diacid chlorides. The reaction scheme is as outlined in Scheme (4).

The elemental analyses of the synthesized azopolyamides are in a good agreement with the calculated values as shown in Table (2). The IR spectra of the azo polymers as in Table (3) showed appearance of peaks at 1520-1526 cm $\mathrm{cm}^{-1}$ and 1630-1774 $\mathrm{cm}^{-1}$ for $(\mathrm{C}=\mathrm{O})$ in $(\mathrm{CONH})$, at 3028-3052 $\mathrm{cm}^{-1}$ and 3314-3426 $\mathrm{cm}^{-1}$ for $(\mathrm{N}-\mathrm{H})$ in $(\mathrm{CONH})$, and disappearance of peak at 701 $\mathrm{cm}^{-1}$ for (-C-Cl). The appearance of peak at 2924-2935 $\mathrm{cm}^{-1}$ for $(\mathrm{CH})_{\text {alph }}$ in samples (XLIII) confirmed the formation of azo polyamide.

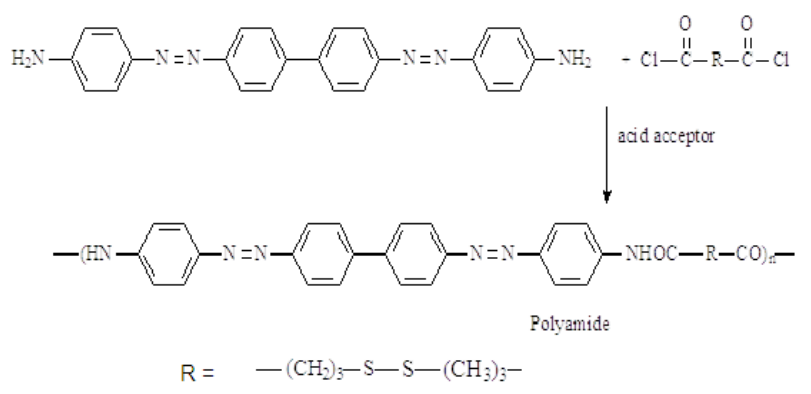

Scheme 4. Synthetic route of copolymer of 4, 4-bis (1"-azo-4"-aminobenzene) biphenyl with Dithiodipropyl dichloride.

\subsubsection{Interfacial Polycondensation}

Interfacial polycondensation of 4 -bis (1"-azo-4"-aminobenzene) biphenyl (II) with various diamines were carried out similarly to interfacial polycondensation used for synthesis of azo polyesters from 4-(2', 4'-dihydroxyphenylazo) phenol (I). The reaction scheme is as outlined in Scheme (4).

The elemental analysis and the IR spectra of the synthesized azopolyamides from interfacial polycondensation were similar to the azopolyamides synthesized from solution polycondensation.

\subsection{Synthesis of p-Aminoazobenzene (III)}

$p$-Aminoazobenzene was prepared by diazotization of aniline to give diazonium salt which was coupled with aniline (N-coupling) to give the hydrazo form. The hydrazo form undergoes rearrangement in acidic medium to form $p$ amino-azobenzene (III) in 75\% yield as shown in Scheme (5). The structure of (III) was confirmed by elemental analysis and the data are listed in Table (2), they were in a good agreement with the calculated values. The IR spectrum showed the appearance of peaks at $1450 \mathrm{~cm}^{-1}$ and $1587 \mathrm{~cm}^{-1}$ which are attributed to $(-\mathrm{N}=\mathrm{N}-)$ group which confirmed the formation of the azodye Table (3).

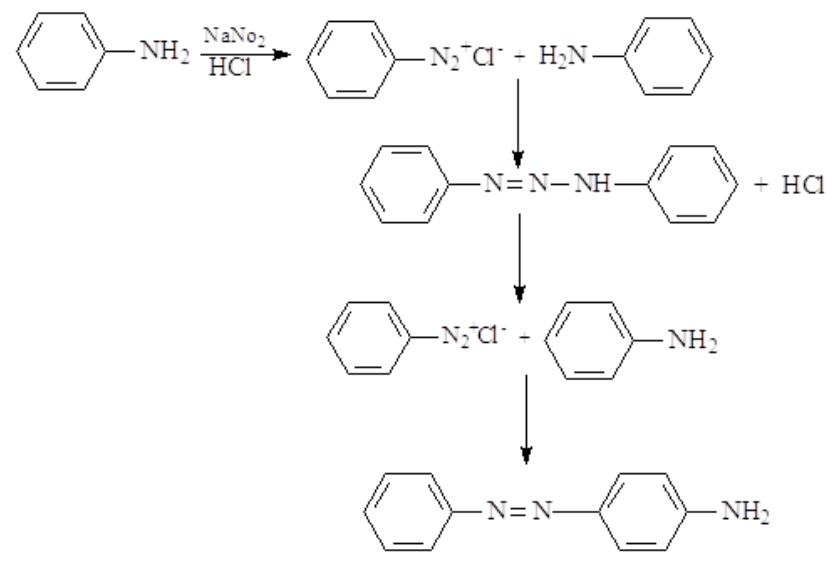

Scheme 5. Synthetic route of p-aminoazobenzene.

\subsection{Synthesis of 4-Methyl-2', 4 -Dihydroxyazobenzene (IV)}

The azo dye 4- methyl-2\, 4 -dihydroxyazobenzene (IV) was prepared by subsequent diazotization and coupling of the diazonium salt of $p$ - toluidine with resorcinol. Diazotization was carried out by the usual procedure using sodium nitrite and hydrochloric acid and coupling was done in moderately alkaline medium at $0-5^{\circ} \mathrm{C}$ as shown in Scheme (6). The yield was $73 \%$, and it was characterized by elemental analysis and IR spectra Tables $(2,3)$. The IR spectra showed the appearance of peaks at $1415 \mathrm{~cm}^{-1}$ and $1612 \mathrm{~cm}^{-1}$ for $(\mathrm{N}=\mathrm{N})$ group thus confirmed the formation of azo dye.

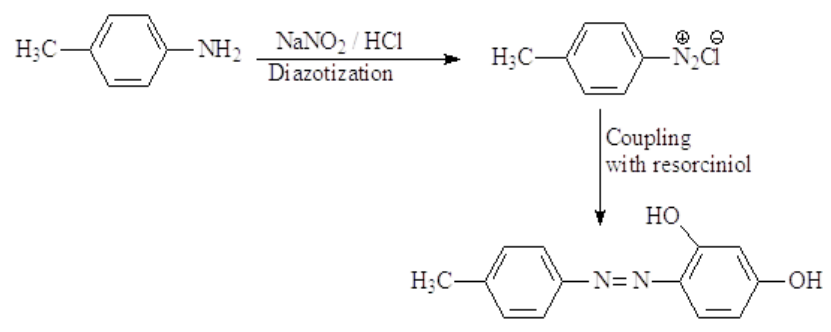

Scheme 6. Synthetic route of 4- methyl-2, 4 -dihydroxyazobenzene (IV).

\subsection{Synthesis of 4- Methyl-4 -Hydroxyazobenzene (IX)}

The azo dye 4- methyl-4 -hydroxyazobenzene (IX) was prepared by subsequent diazotization and coupling of diazonium salt of $p$ - toluidine with phenol. Diazotization was carried out by the usual procedure using sodium nitrite and hydrochloric acid and coupling was done in moderately alkaline medium at $0-5^{\circ} \mathrm{C}$ as shown in Scheme (7). The yield was $70 \%$. The structure is characterized by elemental analysis and IR spectra Tables (3). The IR spectra showed the appearance of peaks at $1458 \mathrm{~cm}^{-1}$ and $1586 \mathrm{~cm}^{-1}$ for $(\mathrm{N}=\mathrm{N})$ group which confirmed the formation of azo dye. 


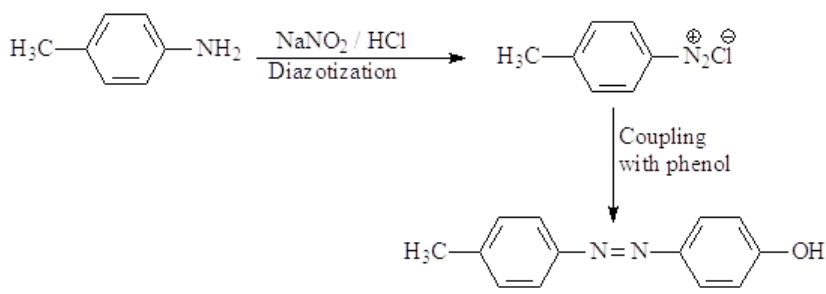

Scheme 7. Synthetic route of 4- methyl-4 -hydroxyazobenzene (IX).

\subsection{Reaction of 4-Methyl-2', 4 -Dihydroxyazobenzene with Acryloyl Chloride}

The modified compound from 4- methyl-2 4-dihydroxyazobenzene with acryloyl chloride was prepared similarly to the modification of $p$ - amino-azobenzene with acryloyl chloride (V). The reaction scheme is as outlined in Scheme (8). The product (XI) was characterized by elemental analysis and IR spectra Tables $(2,3)$. The IR spectra showed the appearance of peaks for $(\mathrm{CH}=\mathrm{CH})$ group at $1664 \mathrm{~cm}^{-1}$ which confirmed the polymer modification.

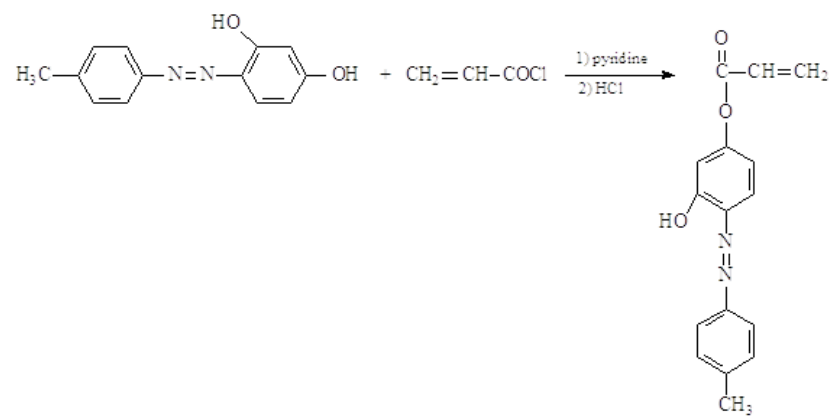

Scheme 8. Synthetic route for reaction of 4- methyl-2, 4 -dihydroxyazobenzene with acryloyl chloride.

\subsection{Reaction of 4- Methyl-4 -Hydroxyazobenzene with Acryloyl Chloride}

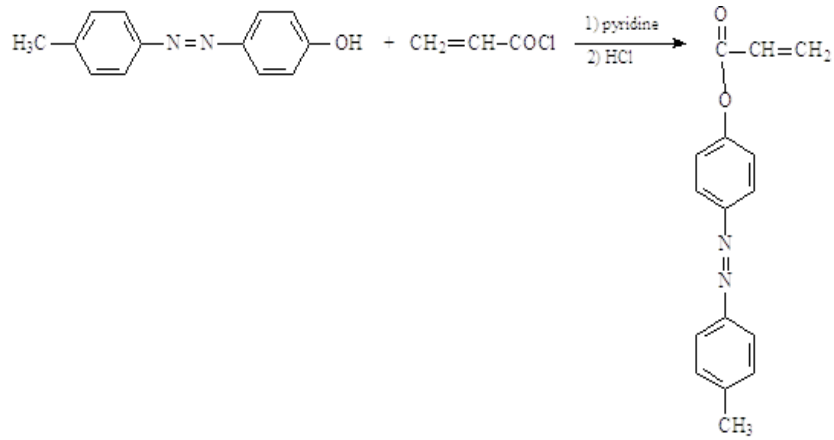

Scheme 9. Synthesis route for reaction of 4- methyl-4-hydroxyazobenzene with acryloyl chloride.

The modified compound from 4-methyl-4-hydroxyazobenzene with acryloyl chloride was prepared similarly to modification of $p$ - aminoazobenzene with acryloyl chloride (X). The reaction is as shown in Scheme (9). The product (XII) was characterized by elemental analysis and IR spectra Tables (3). The IR spectra showed the appearance of peaks at $1728 \mathrm{~cm}^{-1}$ for $(\mathrm{C}=\mathrm{O})$ in ester group and $1631 \mathrm{~cm}^{-1}$ for $(\mathrm{CH}=\mathrm{CH})$ group which confirmed the modification. $\lambda_{\max }(\mathrm{UV})$ in Dichloromethane $354(\mathrm{~nm})$

\subsection{Copolymerization of Modified 4-Methyl-2', 4 -Dihydroxyazobenzene with (MMA) (LVI-LXI)}

Copolymerization of modified 4- methyl-2! 4-dihydroxyazobenzene with MMA was carried out similarly to the copolymerization of the modified $p$-aminoazobenzene with MMA. Copolymer (VII) was synthesized as outlined in Scheme (10).

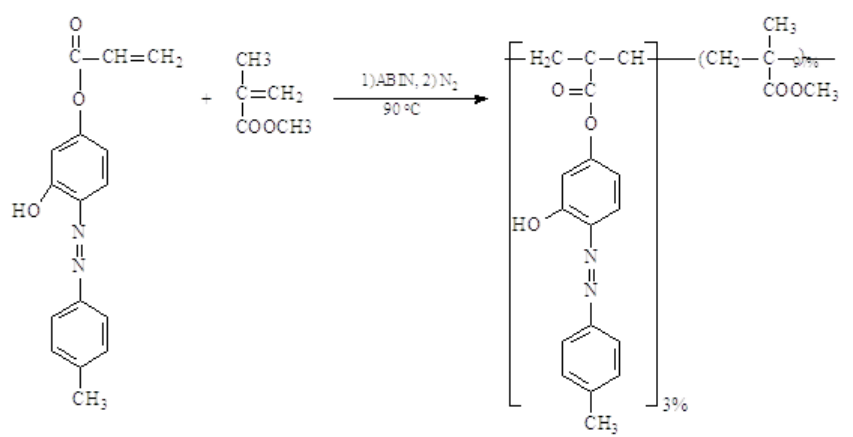

Scheme 10. Synthetic route for copolymerization of modified 4- methyl-2, 4dihydroxyazobenzene with (MMA).

Similarly copolymers (VIII-XI) were prepared by various ratio of modified 4- methyl-2 4 , -dihydroxyazobenzene, and the quantities of reactants used in this copolymerization are listed in Table (1).

Copolymers (VIII-XI) were characterized by elemental analysis and IR spectra cf. Tables $(2,3)$. The IR spectra showed peaks at $1727-1785 \mathrm{~cm}^{-1}$ for $(\mathrm{C}=\mathrm{O})$ in $(\mathrm{COOR})$, and at $1203-1243 \mathrm{~cm}^{-1}$ for $(\mathrm{C}-\mathrm{O})$ in (COOR), the appearance of $(\mathrm{CH})_{\mathrm{alph}}$ group at $2924-2997 \mathrm{~cm}^{-1}$, and the disappearance of $(\mathrm{CH}=\mathrm{CH})$ group at $1664 \mathrm{~cm}^{-1}$ confirmed the polymerization.

${ }^{1} \mathrm{HNMR}$ (in $\mathrm{CD}_{3} \mathrm{Cl}$ ) for (VIII) as shown in table (4) show the appearance of peaks at $\delta=7-7.5 \mathrm{ppm}(m, 8 \mathrm{H}, \mathrm{ArH}), \delta=6.4$ $\operatorname{ppm}(s, \mathrm{H}, 2 \mathrm{O}-\underline{\mathrm{H}}), \delta=3.5-3.7 \mathrm{ppm}\left(t, \mathrm{CH}_{\mathrm{alph}}\right), \delta=1.80-1.9$ $\operatorname{ppm}\left(d, \mathrm{CH}-\underline{\mathrm{CH}}_{2}\right), \delta=1.22-1.46 \mathrm{ppm}\left(s, 6 \mathrm{H}, 2 \underline{\mathrm{C}}_{3}\right)$ and $\delta=2.4$ ppm (s, 3H, Ar- $\left.\mathrm{CH}_{3}\right)$.

Copolymers were also characterized by GPC to determine average molecular weight and number of repeating unit as listed in Table (5). The molecular weight ranged from 2433 to 14977 and the polydispersity ranged from 1.12 to 2.16 .

Ultraviolet absorption spectra for azopolymers (VIII-XI) was registered in methanol and found that $\lambda_{\max }(\mathrm{UV})$ for VIII ( $540 \mathrm{~nm}$ ), LVII ( $381 \mathrm{~nm}$ ) and LX ( $389 \mathrm{~nm})$.

Copolymers were also characterized bythermogravimetric DSC analysis show two glass transition temperature (Tg) first from cooling ranged from 111 to $45{ }^{\circ} \mathrm{C}$ and second from heating ranged from 45 to $111{ }^{\circ} \mathrm{C}$ and also melting temperature was recorded for polymer LX ranged between 96 and $109\left(\mathrm{~J} . g^{-1}\right)$ and melting enthalpy ranged between 32 and $12\left(\mathrm{~J} . g^{-1}\right)$.

DSC analysis show that with increase of aliphatic part and 
molecular weight or decrease of aromatic part the $\mathrm{Tg}$ value increase as a result of decrease the mobility of polymer chain, increase chain rigidity. The high values of $\mathrm{Tg}$ of investigated polymers may be due to high degrees of crystallinity.

TGA data of copolymers (LVII and LX) as in table (6). The thermal stability was evaluated by weight loss ranged from 0.5 to 3.2 at low temperature under a nitogen atomosphere. TGA revealed that the polymers were stable up to from 144 to $171^{\circ} \mathrm{C}$. the decomposition of the polymers was almost complete around $600{ }^{\circ} \mathrm{C}$.

Table 3. I.R. analysis of dyes and its copolymers.

\begin{tabular}{|c|c|c|c|c|c|c|c|c|c|c|c|}
\hline \multirow{2}{*}{$-\mathrm{CH}_{3}$} & \multicolumn{2}{|c|}{$\begin{array}{l}\mathrm{O} \\
\stackrel{\text { C-OMe }}{ }\end{array}$} & \multirow{2}{*}{$(\mathrm{CH})_{\mathrm{alph}}$} & \multicolumn{2}{|c|}{$\mathrm{CH}_{2}=\mathrm{CH}_{2}$} & \multicolumn{2}{|c|}{$\begin{array}{l}\mathrm{O} \\
\mathrm{C}-\mathrm{OAr}\end{array}$} & \multirow{2}{*}{$-\mathrm{N}=\mathrm{N}-$} & \multirow{2}{*}{$\begin{array}{l}1,4 \text { Disubstued } \\
\text { benzene }\end{array}$} & \multirow{2}{*}{$-\mathrm{OH}$} & \\
\hline & $\mathrm{C}-\mathrm{O}$ & $\mathrm{C}=\mathrm{O}$ & & $\mathrm{C}-\mathrm{H}$ & $\mathrm{C}=\mathrm{C}$ & $\mathrm{C}-\mathrm{O}$ & $\mathrm{C}=\mathrm{O}$ & & & & \\
\hline $\begin{array}{l}2850 \\
2923\end{array}$ & --- & - & - & - & - & - & - & $\begin{array}{l}1415 \\
1612\end{array}$ & 820 & 3426 & VIII \\
\hline $\begin{array}{l}2853 \\
2944\end{array}$ & 1210 & 1716 & 2996 & - & - & $\begin{array}{l}1068 \\
1243\end{array}$ & 1631 & $\begin{array}{l}1445 \\
1532\end{array}$ & 754 & 3430 & LVII \\
\hline 2853 & 1242 & 1728 & 2925 & - & - & $\begin{array}{l}1121 \\
1243\end{array}$ & 1619 & $\begin{array}{l}1460 \\
1520\end{array}$ & 699 & 3417 & LX \\
\hline 2927 & --- & --- & --- & - & - & --- & --- & $\begin{array}{l}1458 \\
1586\end{array}$ & 766 & 3431 & IX \\
\hline \multirow[t]{3}{*}{2918} & --- & --- & --- & 3124 & 1631 & 1224 & 1728 & $\begin{array}{l}1457 \\
1584\end{array}$ & 832 & - & XII \\
\hline & & & & & & & & $\begin{array}{l}1453 \\
1517\end{array}$ & 697 & & II \\
\hline & & & & & & & & $\begin{array}{l}1406 \\
1595\end{array}$ & 758 & & XLII \\
\hline
\end{tabular}

Table (4). ${ }^{l} H$ NMR. shifts in ppm for azo dyes and some polymers

\begin{tabular}{|c|c|c|c|c|c|c|}
\hline $\begin{array}{l}\text { Groups } \\
\text { Compound }\end{array}$ & $\langle-$ & -1 & $\mathrm{~N} \underline{\mathrm{H}}$ & $\mathrm{NH}_{2}$ & $\mathrm{CH}_{\underline{2}}$ & $\mathrm{OH}$ \\
\hline I & & $6.5-7.7(\mathrm{~m})$ & & & & $\begin{array}{l}6.3(\mathrm{~d}) \\
12.4(\mathrm{~s})\end{array}$ \\
\hline II & $6.5-8(\mathrm{~m})$ & & & $6.2(\mathrm{~s})$ & & \\
\hline VIII & & $6.5-8.3(\mathrm{~m})$ & & & & $\begin{array}{l}6.4(\mathrm{~d}) \\
12.4(\mathrm{~s})\end{array}$ \\
\hline XLVI & $7-8(\mathrm{~m})$ & & $10.1(\mathrm{~s})$ & $6.5(\mathrm{~s})$ & & \\
\hline LIV & & $6.5-8(\mathrm{~m})$ & & & & $\begin{array}{l}6.3(\mathrm{~d}) \\
12.4(\mathrm{~s})\end{array}$ \\
\hline
\end{tabular}

Table 5. Average weight molecular weight $\left(\overline{\mathrm{M}}_{w}\right)$ and polydispersity index $\left(\overline{\mathrm{M}}_{w} / \overline{\mathrm{M}}_{n}\right.$ ) as evaluated by RI detection (GPC) of copolymers (LVII-LX).

\begin{tabular}{lll}
\hline Sample & $\overline{\mathrm{M}}_{\mathrm{w1}}$ (Da) & $\overline{\mathrm{M}}_{\mathrm{w}} / \overline{\mathrm{M}}_{\mathrm{n}}$ \\
\hline LVII & 6418 & 1.52 \\
LX & 2433 & 1.14 \\
\hline
\end{tabular}

Table 6. Thermogravimetric data of copolymers (LVII-LX).

\begin{tabular}{llllllll}
\hline Sample & \multirow{2}{*}{ Volatile \% } & $\begin{array}{l}\mathbf{T}_{\text {on }} \\
\left({ }^{\circ} \mathbf{C}\right)\end{array}$ & $\begin{array}{l}\mathbf{W}_{\mathbf{1}} \\
\mathbf{( \% )}\end{array}$ & $\begin{array}{l}\mathbf{W}_{\mathbf{2}} \\
(\mathbf{\%})\end{array}$ & $\begin{array}{l}\mathbf{W}_{\mathbf{3}} \\
(\mathbf{\%})\end{array}$ & $\begin{array}{l}\mathbf{W}_{4} \\
(\mathbf{\%})\end{array}$ & $\begin{array}{l}\mathbf{R}_{600} \\
(\%)\end{array}$ \\
\hline LVII & 0.5 & 166 & 2.7 & 28.4 & 48.0 & 7.1 & 13.3 \\
LX & 3.2 & 144 & nd & 23.0 & 13.6 & 14.6 & 45.6 \\
\hline
\end{tabular}

\section{Conclusion}

Azo dye compounds have been synthesized from different amines to form diazonuim salts which then coupled with mono or di phenol. The azo dyes were successfully formed according to the investigation by IR, elemental analysis and $\mathrm{H}^{1} \mathrm{NMR}$, then monomer azo dye were polymerized with diacide chloride and MMAto form polyester or polyamide. The resulted polymeric azo dyes show high M.wt and hidh thermal sability.

\section{References}

[1] Ho M S,Barrett C, Paterson J,E steghamation M, Natansohn A and Rochon P, Macromolecules, 199629,4613.

[2] Yin S, Xu H, shi W, Gao y, Song Y and Wing J, Polymer, $2005,46,7670$.

[3] Nabeshima Y, Shishido A, Kanazawa A, Shiono T, Ikeda t and Hiyama T, Chem Mater1997, 9, 1480.

[4] Hallas G and Towns A D, Dyes pigments, 1997, 33,319.

[5] Towns A D, Dyes pigments, 1999, 42, 3.

[6] T. Mandel., and Y. Inber., Chem. Phys. Lett. 2004, 165, 387.

[7] Hasanain A S. A Majeed, Alaa Yassin Al-Ahmad and Kawkab Ali Hussain, The Preparation, Characterization and the Study of the Linear Optical Properties of a New Azo Compound, Journal of Basrah Researches ((Sciences)) 2011,Vol.37.No. 2,.

[8] E. Saion, Susilawati, A.Doyan,S. Zainal, Z. Azmi, A. Zulkfi, A.R.MohdZaki,K.Z.H. Dahlan and T.Karni, "Changes in the Optical Band Gap and $v$ Absorption Edge of Gamma-Irradiated Polymer Blends “,J. Appl. Sci." , 2005, 5, 10, 1825-1829. 
[9] Gardziella,A. Pilao, L.A., and Know, A., Phenolic Resins: chemistry, Applications,standardization, safety and Ecology, 2000,New York: springer.

[10] Giles C H , A Laboratory Course in Dyeing, 3rd ed ( Socity of Dyers and Colorist, Bradford ) 1974
[11] W, Jie-xiong et al. Application of Polymeric Dyes in Textile Fields, Application of Polymeric Dyes in Textile Fields, The Proceedings of the 3rd International Conference on Functional Molecules 